\title{
Is the Time Course of Clozapine Response Correlated to the Time Course of Clozapine Plasma Levels? A One-Year Prospective Study in Drug-Resistant Patients with Schizophrenia
}

Michele Fabrazzo, M.D., Ph.D., Silvestro La Pia, M.D., Palmiero Monteleone, M.D., Giuseppina Esposito, M.D., Antonio Pinto, M.D., Luigi De Simone, M.D., Rachele Bencivenga, M.D., and Mario Maj, M.D., Ph.D.

The relationship between the time course of clinical response to clozapine and the time course of clozapine plasma levels has never been investigated. In the present study, we assessed prospectively the clinical response to clozapine and the plasma levels of the drug and its major metabolites in 32 drug-resistant patients with schizophrenia kept on a fixed dose of $600 \mathrm{mg} /$ day for 1 year Four of the patients met response criteria at week 4 of treatment. At weeks 8, 12, and 24, new responders were 7, 6 , and 6 , respectively. Nine patients never achieved clinical response. In responders at week 4 , clozapine and clozapine$\mathrm{N}$-oxide plasma levels were significantly higher than in both new responders at weeks 8, 12, and 24 and nonresponders.
In new responders at weeks 8,12 , and 24 , in spite of a fixed clozapine daily dose, mean drug plasma levels progressively rose up to when clinical response occurred; then, the levels remained stable over time. Nonresponders exhibited mean clozapine plasma levels constantly below the value of 260 $\mathrm{ng} / \mathrm{ml}$, with $\mathrm{N}$-demethylation as the preferred metabolic route. The present findings show, for the first time, that the time course of the clinical response to clozapine may be linked to the time course of plasma levels of clozapine and its major metabolites.

[Neuropsychopharmacology 27: 1050-1055, 2002] (C) 2002 American College of Neuropsychopharmacology. Published by Elsevier Science Inc.
KEY WORDS: Schizophrenia; Clozapine; Clinical response; Plasma levels

From the Institute of Psychiatry, University of Naples SUN, Naples, Italy (MF, PM, GE, RB, MM) and Department of Mental Health, Treatment Research Unit, Pollena, Naples, Italy (SLP, AP, LDS). Address correspondence to: M. Fabrazzo, M.D., Ph.D., Institute of Psychiatry, University of Naples SUN, Largo Madonna delle Grazie, 80138 Naples, Italy, Tel.:+39-081-5666517, Fax: +39-081-5666523, E-mail: alfrisa @ tin.it

Received March 23, 2001; revised September 10, 2001; accepted February 20, 2002.

Online publication: $2 / 27 / 02$ at www.acnp.org/citations/ Npp022702252.
Several groups of investigators have assessed the relationships between plasma levels of clozapine and clinical response to treatment. Although effective clozapine plasma level "windows" or response thresholds are still discussed controversially in the literature, the majority of available studies, by using discriminant function analyses or receiver operating characteristic curves, have suggested plasma clozapine concentrations between 350 $\mathrm{ng} / \mathrm{ml}$ and $420 \mathrm{ng} / \mathrm{ml}$ as the optimal break points for predicting response/nonresponse in drug-resistant schizophrenic patients (Perry et al. 1991; Hasegawa et al. 1993; Miller et al. 1994; Potkin et al. 1994; Kronig et al. 1995). Recently, VanderZwaag et al. (1996) reported that the plasma concentration of $250 \mathrm{ng} / \mathrm{ml}$ was the clinically ef- 
fective plasma level cut-off. Furthermore, Bender and Eap (1998) described a patient whose clinical response went up and down concomitantly with the increase and decrease of plasma clozapine levels induced by the addition or withdrawal of fluvoxamine. Therefore, it seems that clozapine plasma levels are correlated with therapeutic response.

Clinical studies have shown that the clinical response to clozapine may occur 1 week up to 1 year after treatment initiation (Meltzer et al. 1989, 1990, 1992; Pickar et al. 1992; Stern et al. 1994; Wilson 1996). The reasons for such a variability in the time course of the response to clozapine treatment are not clear. Changes in plasma levels of the drug may obviously be involved. Indeed, plasma levels of clozapine have been found to vary not only between patients on a similar dose, but also intraindividually among subjects on fixed dose regimens over several weeks of treatment (Centorrino et al. 1994a). Therefore, the possibility exists that the different time courses of response to clozapine may be related to different time courses of the drug plasma levels, even when the drug daily dose is kept constant.

In the present study, we prospectively assessed clinical response and plasma levels of clozapine and its major metabolites in a group of drug-resistant schizophrenic patients kept on a fixed dose of clozapine for 1 year, in the attempt to verify whether temporal changes in clozapine plasma levels were associated with the time course of patients' response to the drug.

\section{METHODS}

The patients included in this study were those participating in a prospectively designed clozapine monitoring program ( $\mathrm{n}=88$ subjects) who completed at least 52 weeks of treatment and had complete data records. They were 32 Caucasian subjects, 21 men and 11 women, meeting both DSM-IV criteria for schizophrenia and Kane's criteria for drug-resistance except one patient who did not met the Kane's criterion of duration of illness of at least 5 years (Kane et al. 1988). Their age range was 24-62 yrs (mean $\pm \mathrm{SD}=34.4 \pm 1.1 \mathrm{yrs}$ ); the duration of their illness ranged from 2 to 32 yrs (11.9 \pm 7.2 yrs). Twelve of them met the DSM-IV criteria for paranoid schizophrenia, 5 for disorganized schizophrenia, 13 for undifferentiated schizophrenia, and 2 for catatonic schizophrenia. All patients provided written informed consent to participate in the study after all the procedures were completely described to them.

In an effort to have consistent baseline conditions, before entering into the study, all the patients' psychoactive drugs except for typical antipsychotics were tapered and discontinued. After patients had been taken on this drug regimen for at least 2 weeks, baseline as- sessment was completed. Then, clozapine treatment was started with dose increments of $25-50 \mathrm{mg}$ every 2 days to bring patients to the dose of $400 \mathrm{mg} /$ day by the end of the week 2. Patients were taken at this dose regimen up to the end of week 4, when a second clinical assessment was performed. Those subjects meeting the response criteria (see below) were maintained on the 400 $\mathrm{mg} /$ day dose regimen up to the end of the study, whereas the remaining patients received further dose increments of $50 \mathrm{mg}$ every 2 days to reach the maximum established dose of $600 \mathrm{mg}$ /day by the end of week 6 , and then were kept on this dose regimen up to week 52. Typical antipsychotics were rapidly tapered and discontinued during the first week of clozapine treatment. Clozapine was administered in 2-3 divided (and approximately equal) doses, with the last dose of the day given between 7:00 P.M. and 8:00 P.M. Patients were hospitalized up to the achievement of their maximum clozapine daily dose; then, they were discharged and clozapine was administered at home by staff nurses, who carefully checked patients' compliance up to the end of the study.

Psychopathological assessment was performed by means of the Expanded Brief Psychiatric Rating Scale (BPRS: 24 items and a scoring from 1 to 7 ) (Lukoff et al. 1986) both before starting clozapine (baseline) and every 2 weeks up to week 52 . Patients were a priori defined responders as they attained a $20 \%$ decrease in the BPRS total score plus a post-treatment BPRS score of 47 or less. These criteria had to be met at two consecutive rating points; responders were classified as such when they first met a priori criteria.

After 4, 8, 12, 24, and 52 weeks of clozapine administration, blood samples were collected by venipuncture before the morning dose of clozapine $(12 \pm 1 \mathrm{~h}$ after the last dose). Plasma was separated by centrifugation and stored at $-20^{\circ} \mathrm{C}$ until assayed for clozapine, N-desmethylclozapine, and clozapine- $\mathrm{N}$-oxide. At baseline and at the same time points of blood drawing, patients' body weight (BW) was recorded. Plasma levels of clozapine, $\mathrm{N}$-desmethylclozapine, and clozapine-N-oxide were determined by reversed phase HPLC and UV detection, as previously described (Volpicelli et al. 1993).

Results were expressed as mean \pm SD and statistically assessed by analysis of variance (ANOVA) with or without repeated measures, post-hoc Tukey's test and $\chi^{2}$ (Chisquare) test with Yate's correction, where appropriate.

\section{RESULTS}

Twenty-three $(71.8 \%)$ of the 32 patients responded according to the a priori response criteria by 12 months of treatment. Of these subjects, 4 (12.5\%) first met response criteria at week $4 ; 7(21.8 \%)$ were first classified as responder at 
Table 1. Demographic and Clinical Characteristics of Patients Classified as Responders and Nonresponders

\begin{tabular}{|c|c|c|c|c|c|c|}
\hline & $\begin{array}{c}\text { All } \\
\text { Responders }\end{array}$ & $\begin{array}{c}\text { New } \\
\text { Responders } \\
\text { at week } 4\end{array}$ & $\begin{array}{c}\text { New } \\
\text { Responders } \\
\text { at week } 8\end{array}$ & $\begin{array}{c}\text { New } \\
\text { Responders } \\
\text { at week } 12\end{array}$ & $\begin{array}{c}\text { New } \\
\text { Responders } \\
\text { at week } 24\end{array}$ & Nonresponders \\
\hline Age (yrs) & $35.1 \pm 11.3$ & $41.5 \pm 16.6$ & $34.5 \pm 12.7$ & $35.0 \pm 12.0$ & $31.6 \pm 3.2$ & $36.3 \pm 10.5$ \\
\hline Age at onset (yrs) & $23.3 \pm 6.1$ & $25.5 \pm 7.5$ & $24.2 \pm 8.4$ & $22.5 \pm 3.8$ & $21.8 \pm 4.9$ & $23.5 \pm 5.8$ \\
\hline Length of illness (yrs) & $11.7 \pm 7.6$ & $16.0 \pm 11.6$ & $10.2 \pm 6.5$ & $12.5 \pm 8.8$ & $9.8 \pm 4.5$ & $12.5 \pm 6.5$ \\
\hline Number of previous hospitalizations & $4.7 \pm 4.7$ & $5.0 \pm 5.4$ & $3.0 \pm 1.9$ & $6.5 \pm 7.2$ & $4.8 \pm 4.2$ & $5.3 \pm 4.7$ \\
\hline Education (yrs) & $8.5 \pm 3.3$ & $7.2 \pm 1.5$ & $9.0 \pm 4.0$ & $7.8 \pm 2.9$ & $9.6 \pm 3.9$ & $8.8 \pm 3.2$ \\
\hline Males/females & $15 / 8$ & $2 / 2$ & $3 / 4$ & $5 / 1$ & $5 / 1$ & $6 / 3$ \\
\hline
\end{tabular}

week $8 ; 6(18.7 \%)$ at week 12; and the remaining $6(18.7 \%)$ at week 24 . Nine $(27.2 \%)$ of 32 patients never achieved clinical response. One-way ANOVA showed no significant difference in the mean age $\left(\mathrm{F}_{4,27}=0.472, \mathrm{NS}\right)$, age at onset $\left(\mathrm{F}_{4,27}=0.271, \mathrm{NS}\right)$, length of the illness $\left(\mathrm{F}_{4,27}=0.525\right.$, $\mathrm{NS})$, number of previous hospitalizations $\left(\mathrm{F}_{4,27}=0.445\right.$, $\mathrm{NS})$, education $\left(\mathrm{F}_{4,27}=0.412, \mathrm{NS}\right)$, baseline BMI $\left(\mathrm{F}_{4,27}=\right.$ $0.933, \mathrm{NS})$, and baseline BPRS total scores $\left(\mathrm{F}_{4,27}=2.518\right.$, NS) between the groups of responders at different time points and nonresponder subjects (Tables 1 and 2). In all groups, Body Mass Index (BMI) progressively increased throughout the study period (Table 2). Two-way ANOVA with repeated measures showed no significant effect for group $\left(\mathrm{F}_{4,27}=1.04, p=.4\right)$ and no significant group $\times$ time interaction $\left(\mathrm{F}_{5,135}=0.44, p=.9\right)$, but a significant effect for time $\left(\mathrm{F}_{5,135}=21.03, p<.0001\right)$, indicating that BMI increased over time with no significant differences among the five response groups. Changes in BMI and BPRS total scores over treatment are shown in Table 2. Twenty-five of the thirty-two patients were smokers (18 were responders and 7 nonresponders); the distribution of smokers between responder and nonresponder patients was not statistically significant $\left(\chi^{2}=0.0008, p=.9\right)$.

Plasma levels of clozapine, $\mathrm{N}$-desmethylclozapine, and clozapine-N-oxide in the different response groups are shown in Figure 1 and 2. As concerns clozapine plasma levels, two-way ANOVA with repeated measures showed significant effects for group $\left(\mathrm{F}_{4,27}=7.19, p<.0001\right)$ and time $\left(\mathrm{F}_{4,108}=17.60, p<.0001\right)$ and a significant group $\times$ time interaction $\left(\mathrm{F}_{4,108}=4.93, p<.0001\right)$, indicating that the time course of plasma clozapine concentrations significantly differed in the five response groups. Indeed, in nonresponder subjects, mean $( \pm \mathrm{SD})$ plasma clozapine levels ranged from $220.1( \pm 101)$ to $251.1( \pm 75.2) \mathrm{ng} / \mathrm{ml}$, were considerably lower than in the other groups, showed only a minimal increase following the enhancement of clozapine daily dose (after week 4 ), and remained stable throughout the study period. Responders at week 4, instead, exhibited mean plasma clozapine levels ranging from $459.5( \pm 149)$ to $473.2( \pm 198) \mathrm{ng} / \mathrm{ml}$, that were considerably stable from the week 4 to week 52 of treatment. Responders at week 8, 12, and 24 exhibited progressive increases in the mean values of plasma clozapine up to the week when they attained clinical response; then, these values showed only minimal changes up to week 52 of treatment. At the time of the clinical response, mean plasma levels of clozapine were 468.3 $( \pm 173) \mathrm{ng} / \mathrm{ml}$ in responders at week $4,588.4( \pm 136) \mathrm{ng} / \mathrm{ml}$ in responders at week $8,409.4( \pm 120)$ in responders at week 12 , and $537.8( \pm 209) \mathrm{ng} / \mathrm{ml}$ in responders at week 24 . These values were significantly higher than correspondent time point values in nonresponder patients $(p<.001$,

Table 2. BMI and BPRS Total Score Changes Throughout Clozapine Treatment in Patients Classified as Responders and Nonresponders (Mean $\pm \mathrm{SD}$ )

\begin{tabular}{|c|c|c|c|c|c|c|}
\hline & Baseline & Week 4 & Week 8 & Week 12 & Week 24 & Week 52 \\
\hline \multicolumn{7}{|l|}{ BMI $\left(\mathrm{Kg} / \mathrm{m}^{2}\right)$} \\
\hline All responders & $27.11 \pm 3.55$ & $27.77 \pm 3.59$ & $28.05 \pm 3.80$ & $28.40 \pm 3.75$ & $29.17 \pm 3.66$ & $29.60 \pm 3.70$ \\
\hline New responders at week 4 & $25.17 \pm 1.32$ & $25.91 \pm 0.65$ & $26.01 \pm 0.68$ & $26.18 \pm 0.57$ & $26.64 \pm 10.26$ & $26.91 \pm 0.69$ \\
\hline New responders at week 8 & $25.60 \pm 3.34$ & $26.44 \pm 3.42$ & $26.63 \pm 3.58$ & $26.96 \pm 3.03$ & $28.00 \pm 3.48$ & $27.98 \pm 3.65$ \\
\hline New responders at week 12 & $28.07 \pm 3.35$ & $28.73 \pm 3.76$ & $29.23 \pm 3.91$ & $29.79 \pm 4.63$ & $30.25 \pm 4.89$ & $30.84 \pm 4.68$ \\
\hline New responders at week 24 & $29.21 \pm 4.18$ & $29.63 \pm 4.24$ & $29.87 \pm 4.56$ & $30.16 \pm 4.04$ & $31.17 \pm 2.69$ & $32.02 \pm 1.98$ \\
\hline Nonresponders & $26.30 \pm 5.84$ & $26.72 \pm 5.91$ & $27.22 \pm 5.99$ & $27.23 \pm 6.04$ & $27.57 \pm 5.19$ & $28.15 \pm 5.66$ \\
\hline \multicolumn{7}{|l|}{ BPRS Total Score } \\
\hline All responders & $72.3 \pm 14.2$ & $56.3 \pm 11.7$ & $52.6 \pm 11.8$ & $44.5 \pm 10.3$ & $38.2 \pm 7.5$ & $37.1 \pm 8.2$ \\
\hline New responders at week 4 & $65.2 \pm 5.8$ & $42.7 \pm 7.8$ & $42.7 \pm 7.8$ & $37.7 \pm 8.5$ & $35.2 \pm 8.5$ & $35.2 \pm 6.1$ \\
\hline New responders at week 8 & $71.4 \pm 12.9$ & $54.1 \pm 5.4$ & $45.4 \pm 1.9$ & $40.8 \pm 6.3$ & $37.1 \pm 8.7$ & $33.2 \pm 7.4$ \\
\hline New responders at week 12 & $68.8 \pm 6.2$ & $60.3 \pm 8.5$ & $56.8 \pm 6.6$ & $41.3 \pm 6.8$ & $38.0 \pm 6.9$ & $36.6 \pm 9.5$ \\
\hline New responders at week 24 & $81.8 \pm 21.5$ & $64.1 \pm 14.5$ & $63.6 \pm 14.7$ & $56.6 \pm 9.2$ & $41.8 \pm 6.7$ & $43.5 \pm 6.6$ \\
\hline Nonresponders & $79.6 \pm 21.6$ & $70.8 \pm 12.9$ & $69.8 \pm 13.6$ & $63.8 \pm 11.4$ & $56.5 \pm 5.1$ & $62.0 \pm 10.9$ \\
\hline
\end{tabular}



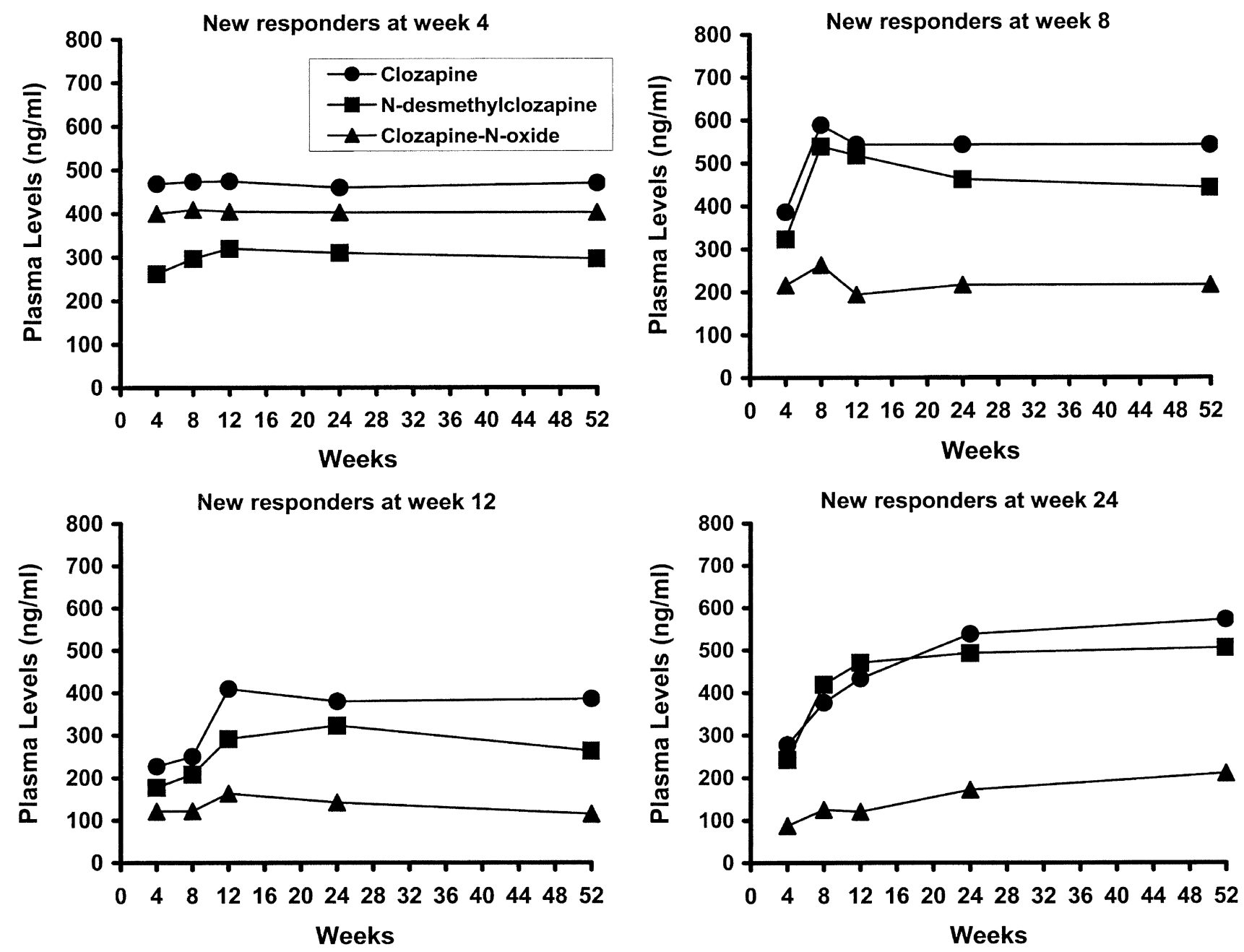

Figure 1. Mean plasma levels of clozapine, N-desmethylclozapine, and clozapine-N-oxide in patients first classified as responders at weeks $4,8,12$, and 24 over 1 year of clozapine treatment.

$p<.001, p<.02$, and $p<.001$ in responders at week 4,8 , 12 , and 24 , respectively).

As concerns N-desmethylclozapine, two-way ANOVA with repeated measures showed significant effects for group $\left(\mathrm{F}_{4,27}=4.23, p<.0001\right)$ and for time $\left(\mathrm{F}_{4,108}=8.21\right.$, $p<.0001)$, but no significant group $\times$ time interaction $\left(\mathrm{F}_{4,108}=1.53, p=.1\right)$, indicating that absolute values of $\mathrm{N}$-desmethylclozapine significantly differed among the groups and showed significant changes over time, although these changes were not significantly different among the five groups (Figures 1 and 2).

As concerns clozapine-N-oxide, two-way ANOVA with repeated measures showed a significant group effect $\left(\mathrm{F}_{4,27}=9.46, p<.0001\right)$, but no significant effect for time $\left(\mathrm{F}_{4,108}=0.49, p=.7\right)$ and no significant group $\times$ time interaction $\left(\mathrm{F}_{4,27}=0.59, p=.8\right)$, indicating that, although absolute values significantly differed among the groups, these values remained considerably stable over treatment and their time course did not significantly differ among the five response groups (Figures 1 and 2).

\section{DISCUSSION}

The most important aspect of this study is that we prospectively assessed the time courses of both clinical response and plasma levels of clozapine and its major metabolites in neuroleptic-resistant schizophrenic patients kept on a fixed daily dose of clozapine up to week 52 of treatment.

From the clinical point of view, we found a 12-month response rate to clozapine of $71.8 \%$; that is high but consistent with data reported in other follow-up studies (Meltzer et al. 1989; Lieberman et al. 1994; Conley et al. 1997). Our data confirm the results of Lieberman et al. (1994), who suggested that the optimal duration of clozapine treatment for establishing its clinical efficacy, at least in fixed dose trials, is no longer than six months. Indeed, we did not observe further responses after 24 weeks of treatment.

Previous studies aiming to identify plasma concentrations of clozapine that could be regarded as optimal break points for predicting response/nonresponse left 


\section{Nonresponders}

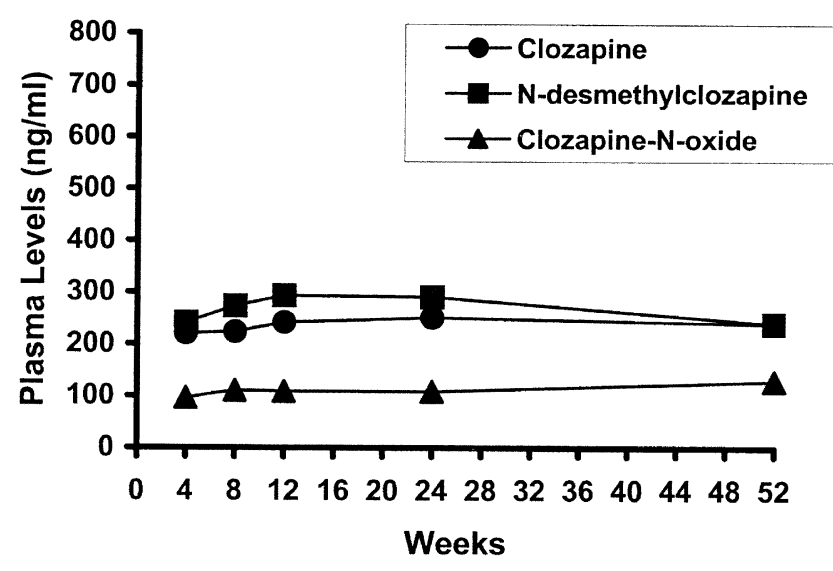

Figure 2. Mean plasma levels of clozapine, N-desmethylclozapine, and clozapine-N-oxide in patients classified as nonresponders over 1 year of clozapine treatment.

unexplained why some patients respond early in the treatment while others do it later. In the present study, we did not aim to identify a clinically effective plasma level cutoff of clozapine, but we grouped the patients on the basis of the time of their clinical response and observed different time courses of plasma concentrations of clozapine and its major metabolites.

In nonresponder patients, mean clozapine plasma levels were constantly below the value of $260 \mathrm{ng} / \mathrm{ml}$ and $\mathrm{N}$-demethylation was the preferred metabolic route, which led to $\mathrm{N}$-desmethylclozapine plasma levels even higher than clozapine itself. In the early responders, instead, $\mathrm{N}$-oxidation of clozapine prevailed over N-demethylation; hence, clozapine-N-oxide plasma levels were considerably increased. Both clozapine-N-oxide and Ndesmethylclozapine are inactive metabolites (Fitton and Heel 1990); however, as clozapine-N-oxide can be reduced to clozapine whereas $\mathrm{N}$-desmethylclozapine does not (Jann et al. 1994), it is possible to speculate that subjects who preferentially metabolize clozapine via $\mathrm{N}$-oxidation may rapidly achieve higher plasma values of the antipsychotic with a greater therapeutic efficacy. Indeed, at week 4, early responders had mean clozapine plasma levels higher than both nonresponders and responders at week 8,12, and 24. Therefore, it could be argued that the preferential N-oxidation of clozapine may be associated with a faster therapeutic response. The metabolic hypothesis needs, however, to be confirmed in larger studies because, as already reported for haloperidol, subsequent experiments have shown that regeneration of reduced haloperidol back to haloperidol is a very minor pathway in humans (Korpi et al. 1985).

In responders at week 8,12 , and 24, in spite of a fixed clozapine daily dose, mean plasma levels of the antipsychotic progressively rose up to when clinical response occurred; then, they remained stable over time. Mean plasma levels of clozapine, measured at the times of clinical responses, did not significantly differ among the responder groups but were significantly higher than the respective time point values in nonresponder patients. Because in early responders mean clozapine plasma levels were at the maximum value already at week 4 and remained stable over treatment, it could be argued that response to clozapine is linked not only to the achievement of the maximum drug plasma value, but also to a stabilization of this value over time.

Although it is easy to understand the rise in clozapine plasma levels occurring in responders at weeks 8,12 , and 24 after the increase of the clozapine daily dose at week 4 , it is not simple to explain the further increase of plasma levels in responders at weeks 12 and 24, when these patients were kept on a fixed daily dose of the drug. Factors known to affect clozapine metabolism (Jann et al. 1993) can be invoked as potentially responsible for these results. None of the patients in our sample, however, received substances known to strongly alter clozapine metabolism, such as anticonvulsants or selective serotonin reuptake inhibitors (Centorrino et al. 1994b; Fabrazzo et al. 2000). Age, caffeine intake, and smoking behavior can be seen as constant variables over the study period and are therefore unlikely to contribute to intraindividual plasma level variability. BW changes were of a comparable magnitude in all groups, and patients' compliance was carefully monitored by staff nurses for the whole study period. The only variable that may be involved in the determinism of these results is gender. Indeed, we had a preponderance of male patients in our late responders. In a previous study (Fabrazzo et al. 1996), we showed that, in patients kept on almost stable daily dose of clozapine for 18 weeks, increases in plasma levels of both clozapine and N-desmethylclozapine occurred from week 6 to week 24 of treatment. We suggested that these increases could be caused by the fact that the percentage of extensive metabolizers of clozapine is high in males, and that part of these extensive metabolizers become poor metabolizers as the treatment goes on, as already described for other antipsychotics (Sakalis et al. 1973; Bergling et al. 1975). In line with this idea, Lin et al. (1994) found that, in a group of 14 male schizophrenic patients on chronic treatment with clozapine, all were poor metabolizers. Therefore, if we speculate that most of our male late responder patients belonged to the category of extensive metabolizers who progressively become poor metabolizers, this might explain our findings. Considerable intraindividual variations in clozapine plasma levels have been reported in samples of patients including prevalently or almost exclusively male subjects and treated with fixed doses of the drug (Centorrino et al. 1994a; Kurz et al. 1998).

This study involved a substantial group of formerly poorly treatment-responsive schizophrenic patients who had been on stable clozapine regimen for 1 year. Our findings show, for the first time, that the time course of 
the clinical response to clozapine is correlated to the time course of plasma levels of clozapine and its major metabolites. If confirmed in future studies, these results may provide a possible explanation for interindividual differences in the clinical response to this antipsychotic drug.

\section{REFERENCES}

Bender S, Eap CB (1998): Very high cytocrome P4501A2 activity and nonresponse to clozapine. Arch Gen Psychiatry 55:1048-1050

Bergling R, Mjorndal T, Orendal L, Rapp W, Wold S (1975): Plasma levels and clinical effect of thioridazine and thiothixene. J Clin Pharmacol 15:178-186

Centorrino F, Baldessarini RJ, Kando JC, Frankenburg FR, Volpicelli SA, Flood JG ((1994): a) Clozapine and metabolites: concentrations in serum and clinical findings during treatment of chronically psychotic patients. J Clin Psychopharmacol 14:119-125

Centorrino F, Baldessarini RJ, Kando JC, Frankenburg FR, Volpicelli SA, Puopolo PR, Flood JG ((1994): b) Serum concentration of clozapine and major metabolites: effects of cotreatment with valproate or fluoxetine. Am J Psychiatry 151:123-126

Conley RR, Carpenter Wt JR, Tamminga CA (1997): Time to clozapine response in a standardized trial. Am J Psychiatry 154:1243-1247

Fabrazzo M, Esposito G, Fusco R, Maj M (1996): Effect of treatment duration on plasma levels of clozapine and $\mathrm{N}$-desmethylclozapine in men and women. Psychopharmacology (Berl) 124:197-200

Fabrazzo M, La Pia S, Monteleone P, Mennella R, Esposito G, Pinto A, Maj M (2000): Fluvoxamine increases plasma and urinary levels of clozapine and its major metabolites in a time-and dose-dependent manner. J Clin Psychopharmacol 20:708-710

Fitton A, Heel RC (1990): Clozapine: a review of its pharmacological properties, and therapeutic use in schizophrenia. Drugs 40:722-747

Hasegawa M, Gutierrez-Esteinon R, Way L, Meltzer HY (1993): Relationship between clinical efficacy and clozapine concentrations in plasma in schizophrenia: effect of smoking. J Clin Psychopharmacol 13:383-390

Jann MW, Grimsley SR, Gray EC, Chang W-H (1993): Pharmacokinetics and pharmacodynamics of clozapine. Clin Pharmacokinet 24:161-176

Jann MW, Lan YWF, Chang W-H (1994): Rapid formation of clozapine in guinea-pigs and man following clozapine$\mathrm{N}$-oxide administration. Arch Int Pharmacod 328:243-250

Kane J, Honigfeld G, Singer J, Meltzer H (1988): Clozapine for the treatment-resistant schizophrenic: a doubleblind comparison with chlorpromazine. Arch Gen Psychiatry 45:789-796

Korpi ER, Costakos DT, Wyart RJ (1985): Rapid formation of reduced haloperidol in guinea pigs following haloperidol administration. Acta Pharmacol Toxicol 56:94-98

Kronig MH, Munne RA, Szymanski S, Safferman AZ, Pollack S, Cooper T, Kane JM, Lieberman JA (1995): Plasma cloz- apine levels and clinical response for treatment-refractory schizophrenic patients. Am J Psychiatry 152:179-182

Kurz M, Hummer M, Kemmler G, Kurzthaler I, Saria A, Fleischhacker WW (1998): Long-term pharmacokinetics of clozapine. Br J Psychiatry 173:341-344

Lieberman JA, Safferman AZ, Pollack S (1994): Clinical effects of clozapine in chronic schizophrenia: response to treatment and predictors of outcome. Am J Psychiatry 151: 1744-1752

Lin SK, Chang W-H, Chung MC, Lan YWF, Jann MW (1994): Disposition of clozapine and desmethylclozapine in schizophrenic patients. J Clin Pharmacol 34:318-324

Lukoff D, Nuechterlein KH, Ventura J (1986): Manual for Expanded Brief Psychiatric Rating Scale (BPRS). Schizophrenia Bull 12:594-602

Meltzer HY (1992): Dimensions of outcome with clozapine. Br J Psychiatry 160:46-53

Meltzer HY, Bastani B, Kwon KY, Ramirez LF, Burnett S, Sharpe J (1989): A prospective study of clozapine in treatment-resistant schizophrenic patients, I: preliminary report. Psychopharmacology (Berl) 99:568-572

Meltzer HY, Burnett S, Bastani B, Ramirez LF (1990): Effects of six months of clozapine treatment on the quality of life of chronic schizophrenic patients. Hosp Community Psychiatry 41:892-897

Miller DD, Fleming F, Holman TL, Jerry PJ (1994): Plasma clozapine concentrations as a predictor of clinical response: a follow-up study. J Clin Psychiatry 55:117-121

Perry PJ, Miller DD, Arndt SV, Cadoret RJ (1991): Clozapine and norclozapine plasma concentrations and clinical response of treatment refractory schizophrenics patients. Am J Psychiatry 148:231-236

Pickar D, Owen RR, Litman RE, Konicki PE, Guitierrez R, Rapaport MH (1992): Clinical and biological response to clozapine in patients with schizophrenia. Arch Gen Psychiatry 43:345-353

Potkin SG, Bera R, Gulasekaram B, Costa J, Hayes S, Jin Y, Richmond G, Carreon D, Sitanggan K, Gerber B, Telford J, Plon L, Plon H, Park L, Chang YJ, Oldroyd J, Cooper TB (1994): Plasma clozapine concentrations predict clinical response in treatment-resistant schizophrenia. J Clin Psychiatry 55:133-136

Sakalis G, Chan TL, Gershon S, Park S (1973): The possible role of metabolites in therapeutic response to chlorpromazine treatment. Psychopharmacologia 32:279-284

Stern RG, Kahn RS, Davidson M, Nora RM, Davis KL (1994): Early response to clozapine in schizophrenia. Am J Psychiatry 151:1817-1818

VanderZwaag C, McGee M, McEvoy JP, Freudenreich O, Wilson WH, Cooper TH (1996): Response of patients with treatment-refractory schizophrenia to clozapine within three serum level ranges. Am J Psychiatry 153: 1579-1584

Volpicelli SA, Centorrino F, Puopolo PR, Kando JC, Frankenburg FR, Baldessarini RJ, Flood JG (1993): Determination of clozapine, norclozapine and clozapine-N-oxide in serum by liquid chromatography. Clin Chem 39:1656-1659

Wilson WH (1996): Time required for initial improvement during clozapine treatment of refractory schizophrenia. Am J Psychiatry 153:951-952 